\title{
The Manufacture of Swedish Filter Paper
}

\author{
Efficiency Obtained in Machine-Made and Hand-Made Processes
}

\author{
By Gustaf Fornstedt
}

There are many different qualities of filter paper, depending upon the use for which they are intended, and they range from an ordinary filtering paper for household use to the fine double-extracted, ashless filter paper intended for very particular analytical work. As a rule the ordinary qualities are machine-made, while, on the other hand, the finer qualities are hand-made.

Machine-made filter paper includes, among other varieties, beer filtering paper, a paper of about 180 pounds weight, made chiefly from cotton rags, and used for filtering beer, as well as for the ordinary filtration of water. The paper is cut square and has $11 / 2$ inch round holes perforated in each angle for the insertion. of four metal bars on which the paper, alternating with perforated zinc plates, is threaded and screwed firmly together. Through these layers of paper and zinc the beer or other liquid is passed at a pressure of about 0.6 atmosphere; the dirt and impurities remain on the paper and the clean and clear liquid passes through.

Machine-made filter paper is used chiefly in the household and for technical purposes, while hand-made filter paper for scientifice analyses is of better quality, though of different grades and make, according to the character of the analysis to be made. The paper being more or less quick filtering, it is made with regard to whether a mere purification of the liquid is intended or whether the substances collected on the paper are to be qualitatively or quantitatively determined.

Some qualities of filter paper, as white and gray woollen paper, are made generally in small paper mills which are not equipped with steam boilers. The rag is furnished "raw" in the beaters and beaten free, but care is taken to avoid lumps. The paper is made on a cylinder machine and taken wet on the hasp, from where it is cut by hand and hung up for drying. A rough mottled surface is produced by means of a coarse wire cylinder running on the wet paper web, the impression remaining very plainly after the paper is air dried.

The cleanest rag is, of course, used as material for filter paper, and it must be of the best quality and sorted with great care. It is important to pick out buttons and any pieces of metal that may be carried by the rags. In new euttings from shirt and collar factories, used in the finest qualities, stray pins and needles give rise to much work and trouble. Iron is, of course, one of the worst impurities in a filtering paper.

The rag is boiled with sodium hydroxide $(\mathrm{NaOH})$ because it gives a lower percentage of ash than lime, and for the same reason the old method of bleaching the half stuff with chlorine is preferred to the use of chloride of lime in bleaching hollanders.

For chlorine bleaching a mixture of manganese, salt and sulphuric acid is used in leaden retorts in about the following proportions

\section{Binoxide of manganese}

Sodium chlorid

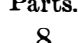

Sulphuric acid. .

Usually, however, a greater quantity of salt is used, because it contains a considerable amount of water.

After the rag is boiled, washed and beaten to halfstuff, it is dried in a centrifugal dryer and spread in layers on wooden poles in the bleaching chamber. This chamber is of concrete, lined with wood. After the bleaching chamber is filled with haltstuff the door is closed and chlorine admitted through an aperture in the roof. After all air has been withdrawn from the chamber it is well sealed, and the halfstuff, after absorbing the chlorine for severa hours, is effectively bleached. Of late, in some mills this bleaching process has been considerably simplified. Liquefied chlorine pressed in steel bombs is used. The bomb is placed in hot water on a scale, a valve on top of the bomb, connected to the bleaching chamber with a rubber hose, is opened, and a certain amount of the liquefied chlorine makes its escape in the gaseous form and is so forced into the bleaching chamber.

The analysis of boiled and bleached halfstuff shows the following ash percentage (silica and lime) :

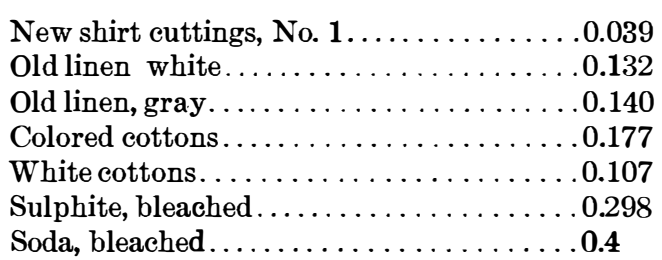

It is, of course, a matter of great importance that the water used in the manufacture of filter paper should be as pure as possible, but it is impossible to a void some asb- containing matter from being introduced to the halfstuff with the water of manufacture, and in the transportation of the halfstuff and the process of drying. Generally the increase is from 0.02 to 0.05 per cent, depending on the state of the weather and the condition of the water.

The time consumed in beating varies according to the nature of the material. Halfstuff freshly bleached requires longer time than that which has been stored some time. Neither too free nor too slow stuff should be used for filter paper. Stuff that is too slow retards filtration-meaning the time taken for a given quantity of water of a certain temperature Paper made of too free stuff fails to keep back the finer grained sediments, such as sulphate of barium, etc.

Among the considerations to keep in mind in the manufacture of filter paper are the rate of filtration demanded, the ash content, resistance to sulphate of barium, fine holes, weight, and impurities.

To produce a filter paper of low ash percentage requires treatment with hydrochloric or hydrofluoric acid or a mixture of these acids, which will remove impurities like ferric oxide, alumina, lime, magnesia, and silica, and paper so treated is practically a pure cellulose paper. With hydrofluoric acid silica is removed, and with hydrochloric acid the other substances enumerated are dissolved away. After treatment with acids the paper should be thoroughly washed with distilled water, to remove the last traces of acidity.

To test the neutral reaction of the paper after washing, a solution of nitrate of silver is used to advantage. The wet paper is squeezed with the hand over a glass funnel and the water filtered into a test-tube. In another testtube containing distilled water a few drops of test solution of nitrate of silver are added, and the same quantity is added to the water expressed from the washed filter paper. The two tubes are then compared against a black background. If not neutral, the water from the filter paper will show an opalescence due to the formation of insoluble chloride of silver from the chlorides remaining in the paper, and further washing is necessary. After this treatment the paper is pressed and hung out in open barns in order to freeze it.

By freezing the paper is made soft and porous, since the ice crystals formed in it serve to drive the fibers apart. Because of this the finest qualities of filter paper only can be made in the winter time in cold countries.

Experiments have been tried of subjecting paper that has been dried in a warm atmosphere to a subsequent freezing operation, in order to impart the desired softness and porosity, but it has been found that paper treated in this way does not become soft, and it never comes up to the standard of the best Swedish filter paper.

Extracted filter paper is practically ashless, the ashes amounting to about 0.015 per cent of the weight of paper, and is of ten negligible not being taken into account in quantitative analytical work.

The most careful, accurate work is necessary in any determination of the ash content of a paper. The instruments required consist of a spacious drying apparatus of copper, two exsiccators, one large and one small, a platinum crucible (about 0.7 ounce) with cover, a stand, a spirit lamp, a blast lamp or Bunsen burner, and a particularly exact balance scale.

The larger exsiccator is used for the dry paper and the smaller for the platinum crucible. Every time the crucible is used it must be cleansed with the finest sand, which has been previously boiled in diluted hydrochloric acid, dried, fired, and kept in the exsiccator until the next time it is used. The scale placed on a table fixed to the wall ought to be of superior construction for fine analytical determinations. Soot must naturally be guarded against in the incinerating operation, as the particles would lead to error in the weighing and conduce to an early deterioration of the crucible.

The manipulations are as follows: The sample is first dried in the drying apparatus at a heat of 190 to $210 \mathrm{deg}$. Fahr. It is then transferred to the exsiccator for fifteen minutes, and afterwards cut in small pieces and put in the cleaned and weighed crucible. The crucible is supported on its stand and the cover adjusted so that air may enter. The crucible is first heated red hot, at which point the hydrocarbon volatilizes; the heat is then increased for twenty minutes, until the crucible glows white hot. After the ash turns white or gray-white the crucible is placed in the exsiccator for ten minutes and weighed; the incineration is then continued until a constant weight is obtained.

If the crucible weighs $a$ gramme, the crucible and paper $b$ gramme, and crucible and asb $c$ gramme, the following formula is obtained.

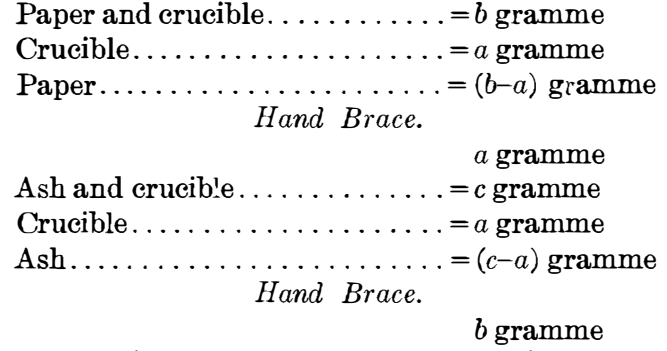

The following figures giving the analysis of ash trom fine filter paper are of interest.

$$
\begin{array}{cc}
\text { I. } & \text { II. } \\
\text { Prof. V. Wich. } & \text { Prof.Brunner. }
\end{array}
$$

$\mathrm{SiO}_{2} \ldots \ldots \ldots \ldots \ldots 31.876 \quad \mathrm{SiO}_{2} \ldots \ldots \ldots \ldots \ldots .63$

$\begin{array}{llll}\mathrm{Al}_{2} \mathrm{O}_{3} \ldots \ldots \ldots \ldots & 14.364 & \mathrm{AlO}_{3} \ldots \ldots \ldots \ldots \ldots & 14.86\end{array}$

$\begin{array}{rllr}\mathrm{Fe}_{2} \mathrm{O}_{3} \ldots \ldots \ldots \ldots & 9.357 & \mathrm{Fe}_{2} \mathrm{O}_{3}+\mathrm{P}_{2} \mathrm{O}_{5} \ldots \ldots & \ldots .08 \\ \mathrm{P}_{2} \mathrm{O}_{5} \ldots \ldots \ldots \ldots \ldots & 0.238 & \mathrm{MnO} \ldots \ldots \ldots \ldots \ldots & 1.74\end{array}$

$\begin{array}{llll}\mathrm{MnO} . \mathrm{Mn}_{2} \mathrm{O}_{3} \ldots \ldots & 7.637 & \mathrm{MgO} \ldots \ldots \ldots \ldots & \mathbf{7 . 8 4}\end{array}$

$\begin{array}{llll}\mathrm{MgO} \ldots \ldots \ldots \ldots & 11.301 & \mathrm{CaO} \ldots \ldots \ldots \ldots \ldots & 26.28\end{array}$

$\mathrm{CaO} \ldots \ldots \ldots \ldots, 21.381 \quad$ Alkali ........... 13.57

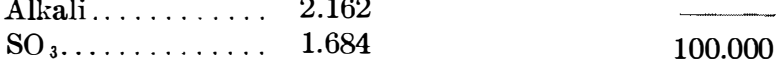

100.000

The best filter paper is made in Grycksbo, Sweden. In the work of manufacture through a long period of years a practical and effective method of extraction has been employed. Being the most northerly hand-paper mill in the world, there is a long, splendid winter which is favorable for freezing the paper. 'The and practically Mountains. Berzelius, the world renowned chemist, esteemed the Swedish filter paper to be the best in the world, and the mill still maintains its reputation,
the paper being in demand over all the old and new world, while the United States takes the bulk of it.

The paper is stamped out in different sizes from 5.5 centimeters to 18.5 centimeters, and is packed in birchbark boxes, which are lined with thin sheets of zinc, hermetically sealed for export to foreign countries.

A good standard of the efficiency of a paper as a filtering medium is represented by the following factors: with a paper having a diameter of 6 inches, the maximum time for filtration of 6 cubic inches of water at $90 \mathrm{deg}$. Fahr. should be 140 seconds, the minimum time 90 seconds.Chemical Engineer.

\section{Wanted: New Uses for Bromine}

A PRIZE of $\$ 2,500$ is offered by the Deutsche Bromkonvention G. m. b. H., Leopoldshall-Stassfurt, Germany, to the discoverer of a process or compound leading to a new or an increased consumption of bromine. The following are some of the conditions attached to this competition: The new discovery must represent a technical innovation and must not adversely affect existing uses of bromine. The process must be applied in practice at the latest one year after the awarding of the prize. The process must, in the opinion of the jury, lead to a considerable increase in the European consumption of bromine at a suitable price. Competitors must send in their processes by January 1, 1914, a the latest.-The Journal of Industrial and Engineering Chemistry.

\section{Some Innovations in the Paper Industry}

Philip B. Sadtler, of the Swenson Evaporator Com pany: of Chicago, Ill., has pointed out that by employing a battery of blow tanks to systematically wash the liquor out of the pulp, this may be accomplished with th least expenditure of water and the highest cleansing effect. This is, moreover, said to be one of the best method for eliminating the objectionable odor of the sulfate pulp mill. Pulp is blown under pressure from the digesters directly into the blow tanks, the battery being used in countercurrent system for washing. The small expenditure of water leaves a minimum of water to be evaporated.

An idea which Mr. Sadtler has included in the desig of the apparatus in the Chesapeake Pulp and Pape Company, at West Point, Va., is the use of waste heat gases from the rotary black ash furnaces to produce the generation of steam in the boiler; this steam is then used to carry out the evaporation of the black liquor in the evaporator. This idea of employing waste heat from special furnaces to generate steam in hoilers is novelty, it is said, in the pulp field.-The Journal of Industrial and Engineering Chemistry. 